\title{
PSYCHE.
}

\section{TWO NEW MELANOPLI FROM LES CHENEAUX ISLANDS, MICHIGAN.}

\author{
BY W. S. BLATCHLEY, INDIANAPOLIS, INDIANA.
}

In August, 1897, after attending the meeting of the Economic Entomologists at Detroit, Michigan, I made a trip by boat via Mackinac Island to Chicago. From Mackinac, one of the most enjoyable and popular excursions is to the Snow (Les Cheneaux) Islands lying I 2 miles to the northeast, near the northern shore of Lake Huron. These islands are a picturesque group, one hundred or more in number, covered with primitive vegetation, and separated by narrow channels. On several of the islands summer hotels are erected and are patronized by many of the disciples of Izaak Walton, who find in the network of channels the finny tribe in untold numbers.

La Salle Island, on which I spent a day, is one of the largest of the group - probably a mile and a half long by a half mile or more wide-densely wooded with spruce, hemlock, cedar, pine, birch and aspen, and with its shores abrupt and in most places 40 to 50 feet above the water level. Only along the immediate shore in front and on either side of the Elliott House have any clearings been made. Here, Cir- cotettix verruculatus (Kirby), Camnula pellucida (Scudd.), Melanoplus bivittatus (Say), M. atlanis (Riley) and $M$. femur-rubrum (De Geer) were plentiful. In one or two other localities were secured small numbers of two additional species which have proven to be undescribed, and which, therefore, form the basis of the present paper.

Melanoplus huroni sp. nov. A brachypterous melanoplian of medium or slightly above medium size; the female rather stout, with tegmina half the length of abdomen; the male more slender, with tegmina covering two thirds of abdomen; cerci tapering gradually from a swollen base to a slender apex; furcula very short, oblong, well separated, with rounded apices; the hind tibiae and lower face of posterior femora blood-red in both sexes. (Belongs to the borckii series as limited by Scudder.)

Male, dark brown, marked with fuscous above, beneath, clay-yellow. Head not prominent, the face testaceous, punctate with fuscous, the labrum and palpi yellowish, the occiput fuscous; vertex moderately tumid, distinctly elevated above the pronotum; eyes moderate in size, slightly more prominent in the male; antennae brownish red, darkening towards the apex, of equal length in both 
sexes. Pronotum distinctly enlarging posteriorly (especially so in female) the disk fuscous or testaceous flecked with fuscous; the posterior lobe darkest; the lateral lobes with a post ocular piceous band on their upper half which extends to the metazona, the lower half testaceous; lateral carinae distinct but not prominent; the median carina sharp and distinct on the metazona, dull and indistinct on the prozona; front margin truncate, hind margin subangulate. Tegmina a little more than twice as long as pronotum, overlapping, sublanceolate, the dorsal and lateral fields angularly separated, brownish, flecked with fuscous, which along the median line of the lateral field is more or less aggregated into a row of small quadrangular spots. Hind femora stout, testaceous, faintly bifasciate with fuscous, the black of geniculation bordered proximally by a yellowish ring, the inferior face a bright blood-red; hind tibiae blood-red, the spines black except at base, ten or eleven in the outer series. Extremity of male abdomen strongly recurved, the subgenital plate terminating in a short conical protuberance. Supra-anal plate triangular with a narrow but deep median sulcus, which broadens basally and lies between sharp walls; furcula consisting of a pair of short, oblong, distant denticulations with rounded apices, lying just outside of the walls of the median sulcus; cerci tapering from a thickened base to a slender, bluntly pointed apex, the distal half slightly curved forward.

Female, much more robust and darker colored, the face, disk of pronotum, and outer face of hind femora, a dark gray where testaceous in the male; the fuscous spots of tegmina larger and more prominent.

Average measurements: Length of body, male, $20 \mathrm{~mm}$., female, $28.5 \mathrm{~mm}$.; antennae, male or female, $9 \mathrm{~mm}$.; tegmina, male, 9.5 mm., female, $12.5 \mathrm{~mm}$; hind femora, male, I2.5 $\mathrm{mm}$., female, $15 \mathrm{~mm}$. Three males, four females, La Salle Island, Michigan, August 17, 1897 .

One hundred yards west of the hotel was a small clearing, an acre or more in extent, where a cabin had formerly stood. Along its margins and over part of its area grew clumps of the wild red raspberry (Rubus strigosus Michx.), and among the numerous remains of stumps were small bunches of wire grass and the trailing vines of the dewberry. Here $M$. huroni had its home, and the females, leaping lubberly from one bunch of grass to another, were readily secured, but the more sprightly males would often have to be chased quite a distance before their capture was effected. Quite a number of both sexes were taken, but unfortunately the cyanide bottle was old and failed to properly do its duty. When the box in which they were dumped was opened it was found that the majority of the females had " come to" and had so chewed and broken their dead companions, that only a few good specimens were left.

Melanoplus islandicus sp. nov. Below the medium in size, the tegmina ovate and a little shorter than the pronotum in both sexes. Cerci of male short, styliform, tapering gradually from a rather broad base; furcula a pair of vẹry short, triangular denticulations. (Puer series as limited by Scudder.)

Male, dark wood brown above; yellowish below. Head not prominent; the face testaceous, varying to clay-yellow; the vertex but little elevated above the pronotum; eyes of both sexes of medium size, equally prominent; antennae uniform testaceous throughout; about three fourths the length of hind femora in both sexes. Pronotum expanding posteriorly but little in male, noticeably so in female, front margin truncate, hind margin broadly rounded; lateral carinae indistinct 
in male, plainly evident in female; median carina distinct on metazona, obsolete or but faintly visible on prozona; disk a uniform dark brown in two specimens, the prozona blotched with fuscous in the remaining two; the lateral lobes with a piceous band on their upper two-thirds which extends to metazona, then setting in again on meso-pleurite continues about half the length of the abdomen, gradually fading posteriorly; bordered below on cheek and prozona with pallid, or testaceous in female, (ivory white in life, as is also the meta-pleurite). Tegmina uniform dark wood brown, narrowly separated dorsally, a very little shorter than pronotum, oval in outline, breadth $I_{\frac{1}{2}}$ in length with apex subangulate; broader in female, breadth $1 \frac{1}{4}$ in length with apex rounded. Hind femora light testaceous on upper and outer faces, faintly and obliquely bifasciate with fuscous; yellowish on inner and lower faces with the fuscous bars plainer on the former, geniculation blackish. Hind tibiae pale red, the spines black, ten in outer series. Extremity of male abdomen entire, moderately recurved; supra-anal plate triangular, a little longer than broad, the sides rather high, the median sulcus narrow, shallow, and terminating near the middle of the plate; the furcula consist of a pair of short, flattish triangular projections of the inner corners of the divided lateral halves of the last dorsal segment and overlie the basal portion of the median sulcus; cerci styliform, a little shorter than the supra-anal plate, tapering strongly on basal half, gradually on apical half to the rather blunt apex.

Female, moderately robust, with colors duller than in the male.

Average measurements: Length of body, male, $15 \mathrm{~mm}$., female, $20 \mathrm{~mm}$.; antennae, male, $7 \mathrm{~mm}$., female, $8 \mathrm{~mm}$; tegmina, male, $4 \mathrm{~mm}$., female, $5 \mathrm{~mm}$.; hind femora, male, $9.5 \mathrm{~mm}$., female, I I mm. Three males, one female, La Salle Island, Michigan, August I 7, I 897 .

Two or three males of islandicus were taken from shady places about the borders of the clearing, in which huroni was found, but the remaining six or eight secured were found along the margins of a narrow pathway which led through the dense woods down the eastern slope of the island. They would leap from the pathway into the mosses and liverworts bordering its sides, and there remain quiet while the intruder passed by. None were found at a distance of more than ten feet from this pathway, though especial search was made for them.

\section{SOME NEW BYTHOSCOPINAE WITH NOTES ON OTHERS.}

BY C. F. BAKER, ALA. POLYTECHNIC INST. AUBURN, ALA.

Bythoscopus fagi Fh.

This is as good a species as any, and occurs sparingly throughout the northeast. It is small, length about $4 \mathrm{~mm}$., the females rufous throughout, paler below, the males with the elytra much darker. The last ventral segment is slightly shorter than preceding and very broadly bilobed. I have a number of males and females from the vicinity of Washington, D. C., and have seen others from New York and Massachusetts. 

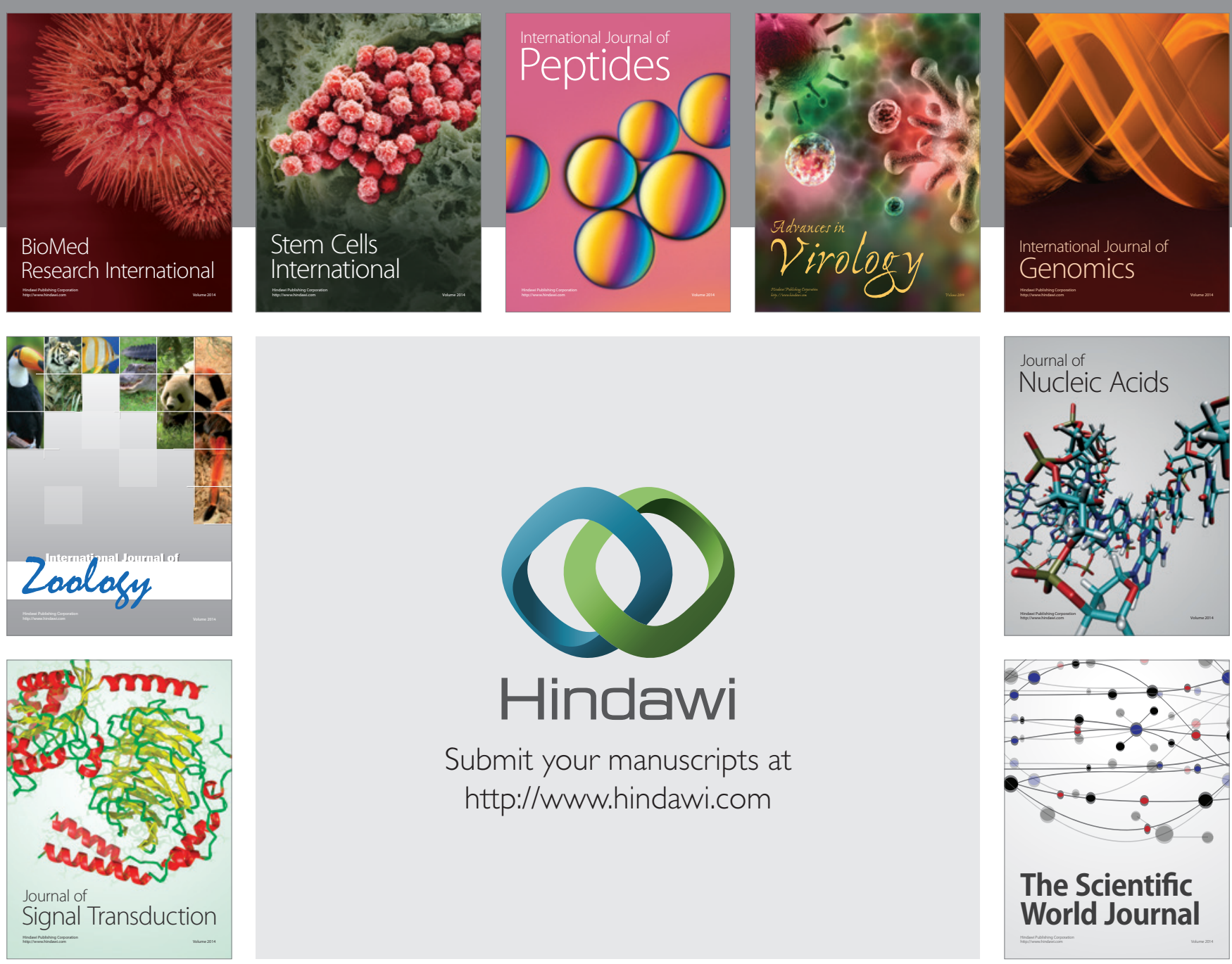

Submit your manuscripts at

http://www.hindawi.com
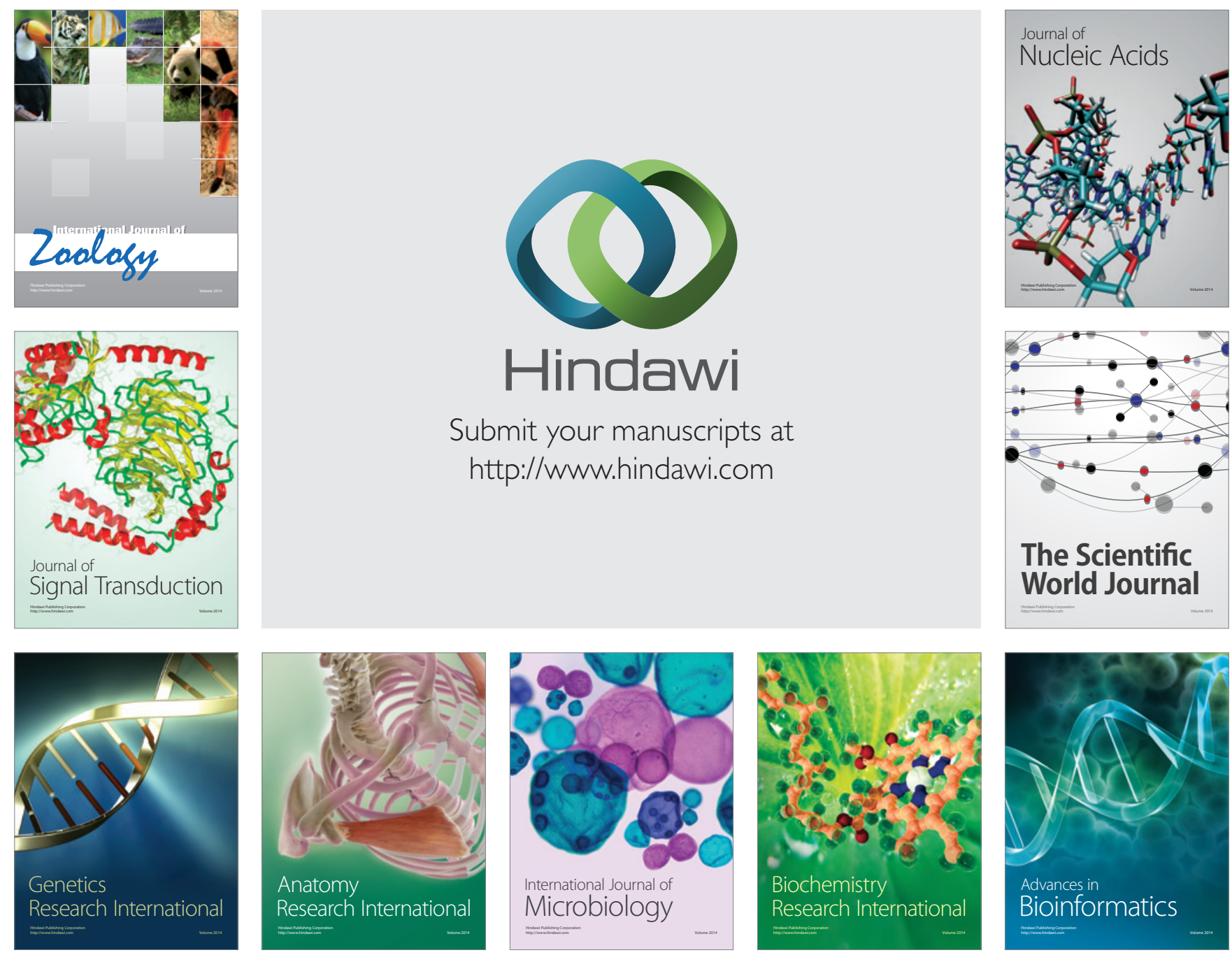

The Scientific World Journal
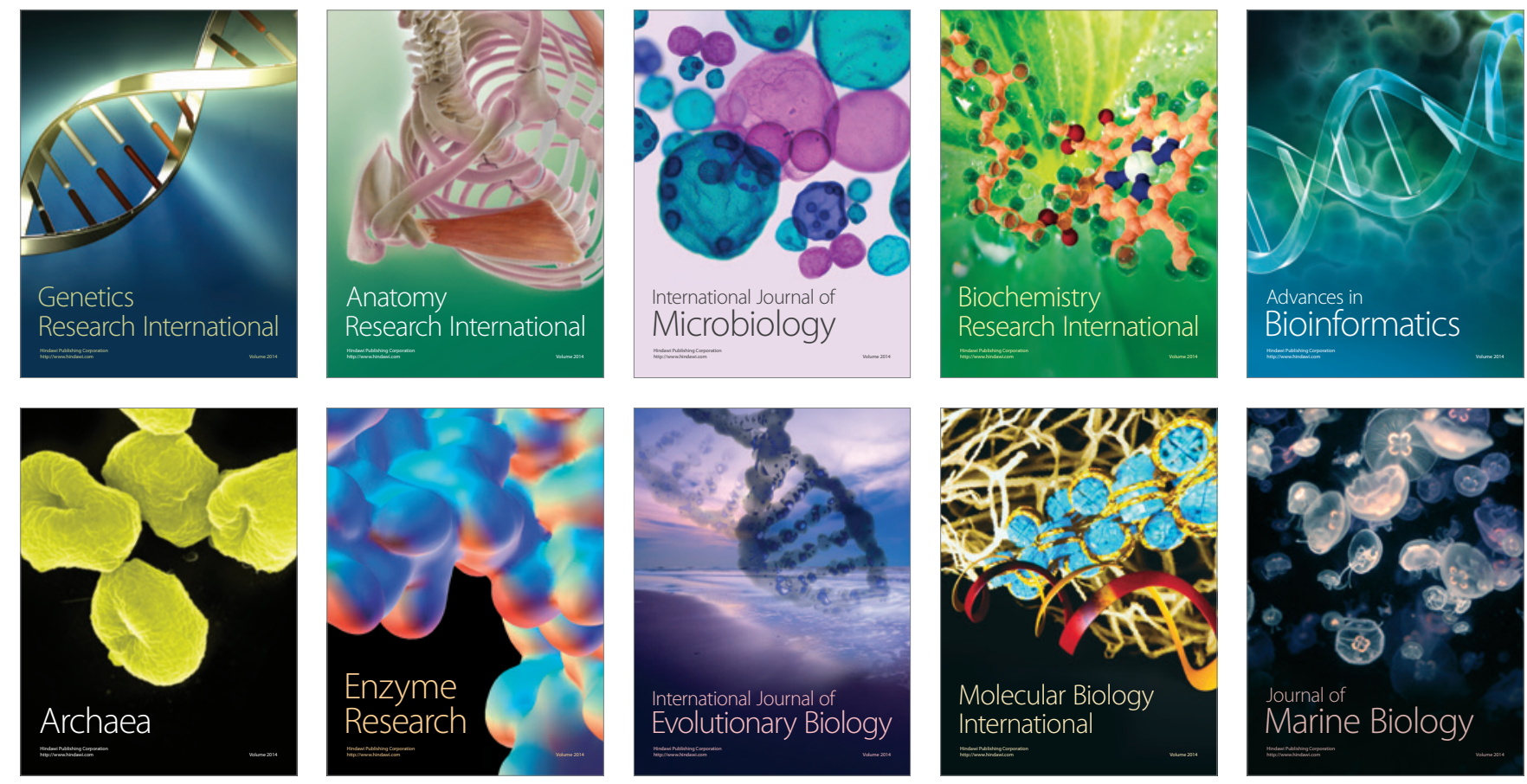